\title{
The effects of tobacco control policies on global smoking prevalence
}

\author{
Luisa S. Flor ${ }^{1}$, Marissa B. Reitsma', Vinay Gupta', Marie $\mathrm{Ng} \oplus^{2}$ and Emmanuela Gakidou $\left(^{1 凶}\right.$
}

\begin{abstract}
Substantial global effort has been devoted to curtailing the tobacco epidemic over the past two decades, especially after the adoption of the Framework Convention on Tobacco Control ${ }^{1}$ by the World Health Organization in 2003. In 2015, in recognition of the burden resulting from tobacco use, strengthened tobacco control was included as a global development target in the 2030 Agenda for Sustainable Development ${ }^{2}$. Here we show that comprehensive tobacco control policies-including smoking bans, health warnings, advertising bans and tobacco taxes-are effective in reducing smoking prevalence; amplified positive effects are seen when these policies are implemented simultaneously within a given country. We find that if all 155 countries included in our counterfactual analysis had adopted smoking bans, health warnings and advertising bans at the strictest level and raised cigarette prices to at least 7.73 international dollars in 2009, there would have been about 100 million fewer smokers in the world in 2017. These findings highlight the urgent need for countries to move toward an accelerated implementation of a set of strong tobacco control practices, thus curbing the burden of smoking-attributable diseases and deaths.
\end{abstract}

Decades after its ill effects on human health were first documented, tobacco smoking remains one of the major global drivers of premature death and disability. In 2017, smoking was responsible for 7.1 (95\% uncertainty interval (UI), 6.8-7.4) million deaths worldwide and $7.3 \%$ (95\% UI, 6.8\%-7.8\%) of total disability-adjusted life years ${ }^{3}$. In addition to the health impacts, economic harms resulting from lost productivity and increased healthcare expenditures are also well-documented negative effects of tobacco use $e^{4,5}$. These consequences highlight the importance of strengthening tobacco control, a critical and timely step as countries work toward the 2030 Sustainable Development Goals ${ }^{2}$.

In 2003, the World Health Organization (WHO) led the development of the Framework Convention on Tobacco Control (FCTC), the first global health treaty intended to bolster tobacco use curtailment efforts among signatory member states ${ }^{1}$. Later, in 2008, to assist the implementation of tobacco control policies by countries, the WHO introduced the MPOWER package, an acronym representing six evidence-based control measures (Table 1) (ref. ${ }^{6}$ ). While accelerated adoption of some of these demand reduction policies was observed among FCTC parties in the past decade ${ }^{7}$, many challenges remain to further decrease population-level tobacco use. Given the differing stages of the tobacco epidemic and tobacco control across countries, consolidating the evidence base on the effectiveness of policies in reducing smoking is necessary as countries plan on how to do better. In this study, we evaluated the association between varying levels of tobacco control measures and age- and sex-specific smoking prevalence using data from 175 countries and highlighted missed opportunities to decrease smoking rates by predicting the global smoking prevalence under alternative unrealized policy scenarios.

Despite the enhanced global commitment to control tobacco use, the pace of progress in reducing smoking prevalence has been heterogeneous across geographies, development status, sex and age ${ }^{8}$; in 2017, there were still 1.1 billion smokers across the 195 countries and territories assessed by the Global Burden of Diseases, Injuries, and Risk Factors Study. Global smoking prevalence in 2017 among men and women aged 15 and older, 15-29 years, 30-49 years and 50 years and older are shown in Extended Data Figs. 1, 2, 3 and 4, respectively. We found that, between 2009 and 2017, current smoking prevalence declined by $7.7 \%$ for men $(36.3 \%$ (95\% UI, 35.9$36.6 \%)$ to $33.5 \%$ (95\% UI, 32.9-34.1\%)) and by $15.2 \%$ for women globally $(7.9 \%$ (95\% UI, $7.8-8.1 \%)$ to $6.7 \%$ (95\% UI, $6.5-6.9 \%)$ ). The highest relative decreases were observed among men and women aged $15-29$ years, at $10 \%$ and $20 \%$, respectively. Conversely, prevalence decreased less intensively for those aged over 50 , at $2 \%$ for men and $9.5 \%$ for women. While some countries have shown an important reduction in smoking prevalence between 2009 and 2017, such as Brazil, suggesting sustained progress in tobacco control, a handful of countries and territories have shown considerable increases in smoking rates among men (for example, Albania) and women (for example, Portugal) over this time period.

In an effort to counteract the harmful lifelong consequences of smoking, countries have, overall, implemented stronger demand reduction measures after the FCTC ratification. To assess national-level legislation quality, the WHO attributes a score to each of the MPOWER measures that ranges from 1 to 4 for the monitoring component $(\mathrm{M})$ and 1-5 for the other components. A score of 1 represents no known data, while scores $2-5$ characterize the overall strength of each measure, from the lowest level of achievement (weakest policy) to the highest level of achievement (strongest policy) ${ }^{6}$. Between 2008 and 2016, although very little progress was made in treatment provision $(\mathrm{O})^{7,9}$, the share of the total population covered by best practice (score $=5) \mathrm{P}, \mathrm{W}$ and $\mathrm{E}$ measures increased (Fig. 1). Notably, however, a massive portion of the global population is still not covered by comprehensive laws. As an example, less than $15 \%$ of the global population is protected by strongly regulated tobacco advertising (E) and the number of people (2.1 billion) living in countries where none or very limited smoke-free policies $(\mathrm{P})$ are in place $($ score $=2)$ is still nearly twice as high as the population (1.1 billion) living in locations with national bans on smoking in all public places (score $=5$ ).

In terms of fiscal policies (R), the population-weighted average price, adjusted for inflation, of a pack of cigarettes across 175 countries with available data increased from I $\$ 3.10$ (where I\$ represents international dollars) in 2008 to I\$5.38 in 2016. However, from an 


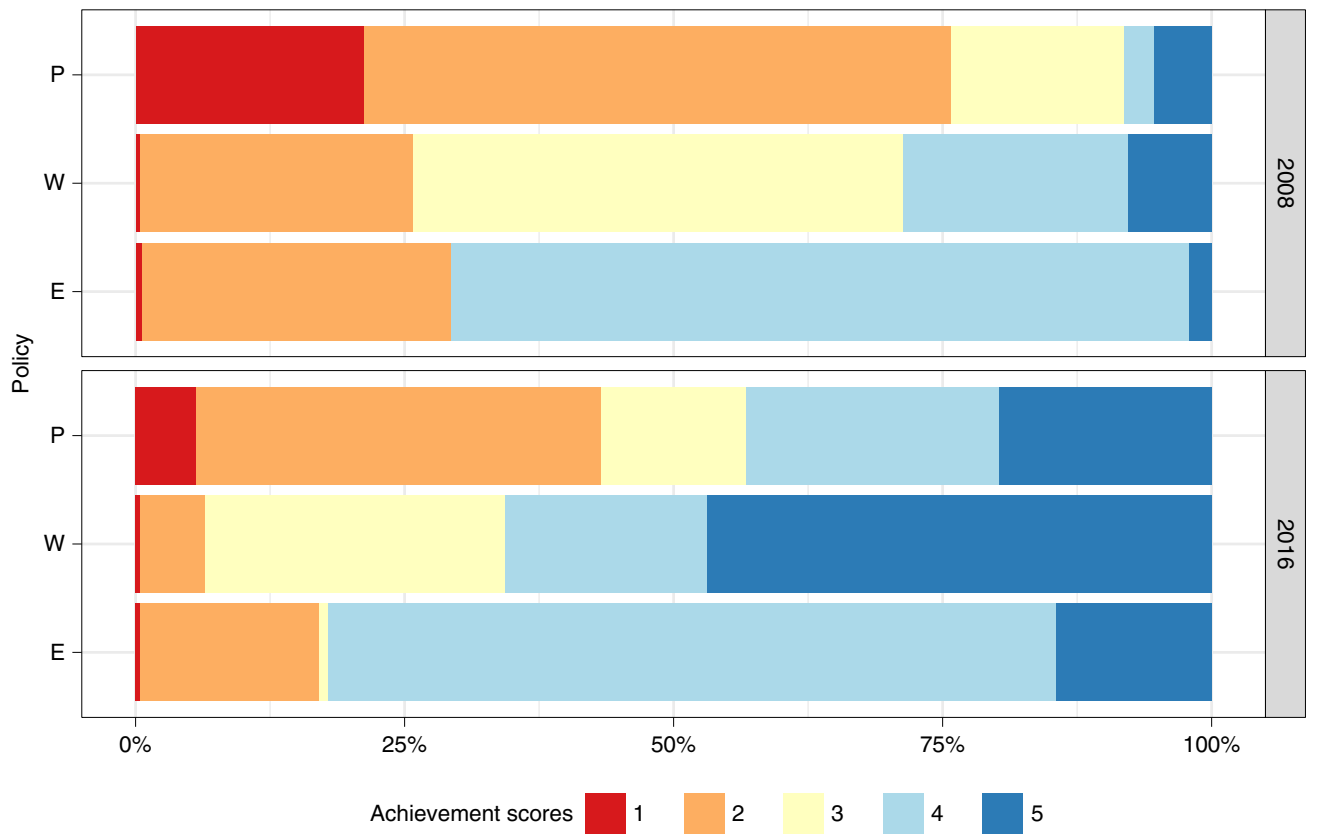

Fig. 1 | Level of coverage of the population aged 15 years and older by comprehensive smoke-free, health warning and advertising policies in 2008 and in 2016. To assess national-level legislation quality, the WHO attributes a score to each MPOWER component that ranges from 1 to 5 for smoke-free $(P)$, health warning $(W)$ and advertising (E) policies. A score of 1 represents no known data or no recent data, while scores 2-5 characterize the overall strength of each policy, from 2 representing the lowest level of achievement (weakest policy), to 5 representing the highest level of achievement (strongest policy).

economic perspective, for prices to affect purchasing decisions, they need to be evaluated relative to income. The relative income price (RIP) of cigarettes is a measure of affordability that reflects, in this study, what proportion of the country-specific per capita gross domestic product (GDP) is needed to purchase half a pack of cigarettes a day for a year. Over time, cigarettes have become less affordable (RIP 2016 > RIP 2008) in about $75 \%$ of the analyzed countries, with relatively more affordable cigarettes concentrated across high-income countries.

Our adjusted analysis indicates that greater levels of achievement on key measures across the P, W and E policy categories and higher RIP values were significantly associated with reduced smoking prevalence from 2009 to 2017 (Table 2). Among men aged 15 and older, each 1-unit increment in achievement scores for smoking bans $(\mathrm{P})$ was independently associated with a $1.1 \%$ ( $95 \%$ UI, -1.7 to $-0.5, P<0.0001)$ decrease in smoking prevalence. Similarly, an increase of 1 point in $\mathrm{W}$ and $\mathrm{E}$ scores was associated with a decrease in prevalence of $2.1 \%(95 \% \mathrm{UI},-2.7$ to -1.6 , $P<0.0001)$ and $1.9 \%$ (95\% UI, -2.6 to $-1.1, P<0.0001)$, respectively. Furthermore, a 10 percentage point increase in RIP was associated with a $9 \%(95 \%$ UI, -12.6 to $-5.0, P<0.0001)$ decrease in overall smoking prevalence. Results were similar for men from other age ranges.

Among women, the magnitude of effect of different policy indicators varied across age groups. For those aged over 15, each 1-point increment in $\mathrm{W}$ and $\mathrm{E}$ scores was independently associated with an average reduction in prevalence of $3.6 \%$ (95\% UI, -4.5 to -2.9 , $P<0.0001)$ and $1.9 \%$ (95\% UI, -2.9 to $-1.8, P=0.002)$, respectively, and these findings were similar across age groups. Smoking ban $(\mathrm{P})$ scores were not associated with reduced prevalence among women aged 15-29 years or over 50 years. However, a 1-unit increase in $P$ scores was associated with a $1.3 \%(95 \% \mathrm{UI},-2.3$ to $-0.2, P=0.016)$ decline in prevalence among women aged $30-49$ years. Lastly, while a 10 percentage point increase in RIP lowered women smoking prevalence by $6 \%$ overall ( $95 \%$ UI, -10.0 to $-2.0, P=0.014$ ), this

\begin{tabular}{|c|c|}
\hline MPOWER component & Definition \\
\hline M & Monitor tobacco use and prevention policies \\
\hline $\mathbf{P}$ & Protect people from tobacco smoke \\
\hline 0 & Offer help to quit tobacco use \\
\hline $\mathbf{W}$ & Warn about the dangers of tobacco \\
\hline $\mathbf{E}$ & $\begin{array}{l}\text { Enforce bans on tobacco advertising, promotion } \\
\text { and sponsorship }\end{array}$ \\
\hline $\mathbf{R}$ & Raise taxes on tobacco \\
\hline \multicolumn{2}{|c|}{$\begin{array}{l}\text { MPOWER is a policy package intended to assist in the country-level implementation of } \\
\text { cost-effective interventions to prevent and reduce tobacco use, as ratified by the WHO FCTC. } \\
\text { Other than demand reduction measures, MPOWER encourages countries to develop surveillance } \\
\text { systems to monitor the tobacco epidemic. Each of the MPOWER components reflects one or more } \\
\text { provisions described in the FCTC. }\end{array}$} \\
\hline
\end{tabular}

finding was not statistically significant when examining reductions in prevalence among those aged 50 and older (Table 2).

If tobacco control had remained at the level it was in 2008 for all 155 countries (with non-missing policy indicators for both 2008 and 2016; Methods) included in the counterfactual analysis, we estimate that smoking prevalence would have been even higher than the observed 2017 rates, with 23 million more male smokers and 8 million more female smokers (age $\geq 15$ ) worldwide (Table 3 ). Out of the counterfactual scenarios explored, the greatest progress in reducing smoking prevalence would have been observed if a combination of higher prices-resulting in reduced affordability levels-and strictest $\mathrm{P}, \mathrm{W}$ and $\mathrm{E}$ laws had been implemented by all countries, leading to lower smoking rates among men and women from all age groups and approximately 100 million fewer smokers across all countries (Table 3). Under this policy scenario, the greatest relative decrease in prevalence would have been seen among those aged 15-29 for 
Table 2 | Percentage changes in current smoking prevalence based on fixed effect coefficients from adjusted mixed effect linear regression models, by policy component, sex and age group

\begin{tabular}{|c|c|c|c|c|c|c|c|c|c|}
\hline \multirow{2}{*}{$\begin{array}{l}\text { Age and } \\
\text { policy } \\
\text { component }\end{array}$} & \multicolumn{3}{|c|}{ Men } & \multicolumn{3}{|c|}{ Women } & \multicolumn{3}{|c|}{ Both sexes } \\
\hline & $\begin{array}{l}\text { Relative } \\
\text { change }\end{array}$ & $95 \%$ UI & $P$ & $\begin{array}{l}\text { Relative } \\
\text { change }\end{array}$ & $95 \%$ UI & $P$ & $\begin{array}{l}\text { Relative } \\
\text { change }\end{array}$ & $95 \%$ UI & $P$ \\
\hline \multicolumn{10}{|l|}{$\geq 15$} \\
\hline RIP & -0.9 & $\begin{array}{l}-1.3 \text { to } \\
-0.5\end{array}$ & $<0.001$ & -0.6 & -1.0 to -0.2 & 0.014 & -0.7 & -1.1 to -0.4 & 0.001 \\
\hline P & -1.1 & -1.7 to -0.5 & $<0.001$ & -0.9 & -1.7 to 0.1 & 0.065 & -1.0 & -1.6 to -0.5 & 0.001 \\
\hline W & -2.1 & -2.7 to -1.6 & $<0.001$ & -3.6 & -4.5 to -2.9 & $<0.001$ & -2.1 & -2.6 to -1.5 & $<0.001$ \\
\hline$E$ & -1.9 & -2.6 to -1.1 & $<0.001$ & -1.9 & -2.9 to -1.8 & 0.002 & -1.8 & -2.5 to -1.8 & $<0.001$ \\
\hline \multicolumn{10}{|l|}{$15-29$} \\
\hline RIP & -1.1 & -1.6 to -0.6 & $<0.001$ & -0.8 & -1.5 to -0.1 & 0.016 & -1.1 & -1.6 to -0.6 & 0.001 \\
\hline $\mathrm{P}$ & -1.0 & -1.7 to -0.3 & 0.003 & -0.8 & -1.9 to 0.4 & 0.177 & -0.9 & -1.6 to -0.3 & 0.008 \\
\hline W & -2.1 & -2.7 to -1.4 & $<0.001$ & -4.0 & -5.0 to -3.0 & $<0.001$ & -2.1 & -2.8 to -1.4 & $<0.001$ \\
\hline$E$ & -2.2 & -3.1 to -2.2 & $<0.001$ & -2.5 & -4.0 to -2.5 & $<0.001$ & -2.1 & -2.9 to -1.1 & $<0.001$ \\
\hline \multicolumn{10}{|l|}{$30-49$} \\
\hline RIP & -1.1 & -1.6 to -0.6 & $<0.001$ & -0.6 & -1.1 to -0.1 & 0.016 & -0.9 & -1.3 to -0.4 & 0.001 \\
\hline$P$ & -1.1 & -1.8 to -0.5 & $<0.001$ & -1.3 & -2.3 to -0.2 & 0.016 & -1.2 & -1.8 to -0.6 & 0.001 \\
\hline W & -2.4 & -3.0 to -1.8 & $<0.001$ & -3.5 & -4.5 to -2.6 & $<0.001$ & -2.2 & -2.8 to -1.5 & $<0.001$ \\
\hline$E$ & -1.7 & -2.5 to -1.7 & $<0.001$ & -1.7 & -3.1 to -1.7 & 0.010 & -1.6 & -2.5 to -1.6 & 0.001 \\
\hline \multicolumn{10}{|l|}{$\geq 50$} \\
\hline RIP & -0.6 & -0.9 to -0.3 & $<0.001$ & -0.2 & -0.3 to 0.0 & 0.119 & -0.3 & -0.6 to -0.1 & 0.011 \\
\hline$P$ & -1.2 & -1.8 to -0.6 & $<0.001$ & -0.1 & -1.0 to 0.8 & 0.797 & -1.0 & -1.5 to -0.4 & 0.001 \\
\hline w & -1.9 & -2.4 to -1.3 & $<0.001$ & -2.9 & -3.7 to -2.1 & $<0.001$ & -1.7 & -2.2 to -1.2 & $<0.001$ \\
\hline $\mathrm{E}$ & -1.9 & -2.7 to -1.9 & $<0.001$ & -2.0 & -3.0 to -2.0 & $<0.001$ & -1.9 & -2.6 to -1.9 & $<0.001$ \\
\hline
\end{tabular}

The models examined the adjusted association between smoke-free (P), health warning (W) and advertising (E) achievement scores, as well as cigarette's affordability (RIP) and current smoking prevalence, from 2009 to 2017 , across 175 countries ( $n=823$ country-years). Linear mixed models were fitted by maximum likelihood and $t$-tests used Satterthwaite approximations to degrees of freedom. $P$ values were considered statistically significant if $<0.05$.

both sexes, resulting in 26.6 and 6.5 million fewer young male and female smokers worldwide in 2017, respectively.

Our findings reaffirm that a wide spectrum of tobacco demand reduction policies has been effective in reducing smoking prevalence globally; however, it also indicates that even though much progress has been achieved, there is considerable room for improvement and efforts need to be strengthened and accelerated to achieve additional gains in global health. A growing body of research points to the effectiveness of tobacco control measures ${ }^{10-12}$; however, this study covers the largest number of countries and years so far and reveals that the observed impact has varied by type of control policy and across sexes and age groups. In high-income countries, stronger tobacco control efforts are also associated with higher cessation ratios (that is, the ratio of former smokers divided by the number of ever-smokers (current and former smokers)) and decreases in cigarette consumption ${ }^{13,14}$.

Specifically, our results suggest that men are, in general, more responsive to tobacco control interventions compared to women. Notably, with prevalence rates for women being considerably low in many locations, variations over time are more difficult to detect; thus, attributing causes to changes in outcome can be challenging. Yet, there is already evidence that certain elements of tobacco control policies that play a role in reducing overall smoking can have limited impact among girls and women, particularly those of low socioeconomic status ${ }^{15}$. Possible explanations include the different value judgments attached to smoking among women with respect to maintaining social relationships, improving body image and hastening weight control ${ }^{16}$.
Tax and price increases are recognized as the most impactful tobacco control policy among the suite of options under the MPOWER framework ${ }^{10,14,17}$, particularly among adolescents and young adults ${ }^{18}$. Previous work has also demonstrated that women are less sensitive than men to cigarette tax increases in the $\mathrm{USA}^{19}$. Irrespective of these demographic differences, effective tax policy is underutilized and only six countries-Argentina, Chile, Cuba, Egypt, Palau and San Marino-had adopted cigarette taxes that corresponded to the WHO-prescribed level of $70 \%$ of the price of a full pack by $2017\left(\right.$ ref. $\left.{ }^{20}\right)$. Cigarettes also remain highly affordable in many countries, particularly among high-income nations, an indication that affordability-based prescriptions to countries, instead of isolated taxes and prices reforms, are possibly more useful as a tobacco control target. In addition, banning sales of single cigarettes, restricting legal cross-border shopping and fighting illicit trade are required so that countries can fully experience the positive effect of strengthened fiscal policies.

Smoke-free policies, which restrict the opportunities to smoke and decrease the social acceptability of smoking ${ }^{17}$, also affect population groups differently. In general, women are less likely to smoke in public places, whereas men might be more frequently influenced by smoking bans in bars, restaurants, clubs and workplaces across the globe due to higher workforce participation rates ${ }^{16}$. In addition to leading to reduced overall smoking rates, as indicated in this study, implementing complete smoking bans (that is, all public places completely smoke-free) at a faster pace can also play an important role in minimizing the burden of smoking-attributable 
Table 3 | Observed and simulated reduction in global smoking prevalence and in the total number of smokers under four counterfactual scenarios, by sex and age group

\begin{tabular}{|c|c|c|c|c|c|c|c|c|c|c|}
\hline \multirow{2}{*}{$\begin{array}{l}\text { Age and } \\
\text { sex }\end{array}$} & \multicolumn{2}{|c|}{ Observed-GBD 2017} & \multicolumn{2}{|c|}{ Scenario 1} & \multicolumn{2}{|c|}{ Scenario 2} & \multicolumn{2}{|c|}{ Scenario 3} & \multicolumn{2}{|c|}{ Scenario 4} \\
\hline & $\begin{array}{l}2017 \text { prevalence } \\
(95 \% \text { UI) }\end{array}$ & $\begin{array}{l}\text { Number of } \\
\text { smokers } \\
\text { (in } \\
\text { millions) }\end{array}$ & $\begin{array}{l}\text { Relative \% } \\
\text { change in } \\
\text { prevalence }\end{array}$ & $\begin{array}{l}\text { Change } \\
\text { in the } \\
\text { number of } \\
\text { smokers (in } \\
\text { millions) }\end{array}$ & $\begin{array}{l}\text { Relative \% } \\
\text { change in } \\
\text { prevalence }\end{array}$ & $\begin{array}{l}\text { Change } \\
\text { in the } \\
\text { number of } \\
\text { smokers (in } \\
\text { millions) }\end{array}$ & $\begin{array}{l}\text { Relative \% } \\
\text { change in } \\
\text { prevalence }\end{array}$ & $\begin{array}{l}\text { Change } \\
\text { in the } \\
\text { number of } \\
\text { smokers (in } \\
\text { millions) }\end{array}$ & $\begin{array}{l}\text { Relative \% } \\
\text { change in } \\
\text { prevalence }\end{array}$ & $\begin{array}{l}\text { Change in } \\
\text { the number } \\
\text { of smokers } \\
\text { (in millions) }\end{array}$ \\
\hline \multicolumn{11}{|l|}{ Men } \\
\hline$\geq 15$ & $37.1(36.4-37.8)$ & 768.1 & $+3 \%$ & +22.7 & $-5.9 \%$ & -45.5 & $-4.9 \%$ & -37.9 & $-10.6 \%$ & -81.7 \\
\hline $15-29$ & $29.8(28.6-30.9)$ & 192.3 & $+3.5 \%$ & +6.7 & $-9.2 \%$ & -17.4 & $-5.2 \%$ & -9.9 & $-14 \%$ & -26.6 \\
\hline $30-49$ & $44.1(42.7-45.4)$ & 336.9 & $+2.9 \%$ & +9.7 & $-6.3 \%$ & -20.7 & $-4.6 \%$ & -15.3 & $-10.6 \%$ & -35.4 \\
\hline$\geq 50$ & $37(35.8-38.3)$ & 238.9 & $+2.6 \%$ & +6.3 & $-3.2 \%$ & -7.4 & $-5.3 \%$ & -12.7 & $-8.4 \%$ & -19.7 \\
\hline \multicolumn{11}{|l|}{ Women } \\
\hline$\geq 15$ & $7.4(7.1-7.6)$ & 156 & $+4.9 \%$ & +7.6 & $-5 \%$ & -7.8 & $-7.3 \%$ & -11.4 & $-12 \%$ & -18.7 \\
\hline $15-29$ & $6.1(5.7-6.5)$ & 38.7 & $+6.1 \%$ & +2.4 & $-8.4 \%$ & -3.5 & $-8.1 \%$ & -3.3 & $-15.9 \%$ & -6.5 \\
\hline $30-49$ & $8.1(7.7-8.5)$ & 61.4 & $+4.9 \%$ & +3.2 & $-5.1 \%$ & -3.4 & $-7.8 \%$ & -4.9 & $-12.5 \%$ & -8.1 \\
\hline$\geq 50$ & $7.9(7.4-8.5)$ & 55.9 & $+3.4 \%$ & +2 & $-1 \%$ & -0.9 & $-5.5 \%$ & -3.2 & $-6.5 \%$ & -4.1 \\
\hline
\end{tabular}

Prevalence and number of smokers across 155 countries included in the counterfactual analysis (non-missing policy/price indicators for both 2008 and 2016). Alternative policy scenarios are: (1) if achievement scores and cigarette's affordability (RIP) remained at the level they were at in 2008; (2) if the price of a cigarette pack was $1 \$ 7.73$ or higher, a price that represents the 90 th percentile of observed prices across all 175 countries and years; $(3)$ if all countries had implemented each of the smoke-free $(P)$, health warning $(W)$ and advertising $(E)$ policies at the highest level $($ score $=5$ ); and (4) if countries had implemented both higher cigarette prices and P, W and E policies at the highest level.

diseases and deaths among nonsmokers. In 2017 alone, $2.18 \%(95 \%$ UI, $1.8-2.7 \%)$ of all deaths were attributable to secondhand smoke globally, with the majority of the burden concentrated among women and children ${ }^{21}$.

Warning individuals about the harms of tobacco use increases knowledge about the health risks of smoking and promotes changes in smoking-related behaviors, while full advertising and promotion bans-implemented by less than $20 \%$ of countries in 2017 (ref. ${ }^{20}$ )are associated with decreased tobacco consumption and smoking initiation rates, particularly among youth ${ }^{17,22,23}$. Large and rotating pictorial graphic warnings are the most effective in attracting smokers' attention but are lacking in countries with high numbers of smokers, such as China and the USA ${ }^{20}$. Adding best practice health warnings to unbranded packages seems to be an effective way of informing about the negative effects of smoking while also eliminating the tobacco industry's marketing efforts of using cigarette packages to make these products more appealing, especially for women and young people who are now the prime targets of tobacco companies ${ }^{24,25}$.

While it is clear that strong implementation and enforcement are crucial to accelerating progress in reducing smoking and its burden globally, our heterogeneous results by type of policy and demographics highlight the challenges of a one-size-fits-all approach in terms of tobacco control. The differences identified illustrate the need to consider the stages ${ }^{26}$ of the smoking epidemics among men and women and the state of tobacco control in each country to identify the most pressing needs and evaluate the way ahead. Smoking patterns are also influenced by economic, cultural and political determinants; thus, future efforts in assessing the effectiveness of tobacco control policies under these different circumstances are of value. As tobacco control measures have been more widely implemented, tobacco industry forces have expanded and threaten to delay or reverse global progress ${ }^{27}$. Therefore, closing loopholes through accelerated universal adoption of the comprehensive set of interventions included in MPOWER, guaranteeing that no one is left unprotected, is an urgent requirement as efforts toward achieving the Sustainable Development Goals by 2030 are intensified.

\section{Online content}

Any methods, additional references, Nature Research reporting summaries, source data, extended data, supplementary information, acknowledgements, peer review information; details of author contributions and competing interests; and statements of data and code availability are available at https://doi.org/10.1038/ s41591-020-01210-8.

Received: 28 May 2020; Accepted: 10 December 2020;

Published online: 21 January 2021

\section{References}

1. World Health Organization. WHO Framework Convention on Tobacco Control https://www.who.int/fctc/text_download/en/ (2003).

2. United Nations. Transforming Our World: the 2030 Agenda for Sustainable Development https://sustainabledevelopment.un.org/post2015/ transformingourworld/publication (2015).

3. Stanaway, J. D. et al. Global, regional, and national comparative risk assessment of 84 behavioural, environmental and occupational, and metabolic risks or clusters of risks for 195 countries and territories, 1990-2017: a systematic analysis for the Global Burden of Disease Study 2017. Lancet 392, 1923-1994 (2018).

4. Jha, P. \& Peto, R. Global effects of smoking, of quitting, and of taxing tobacco. N. Engl. J. Med. 370, 60-68 (2014).

5. Ekpu, V. U. \& Brown, A. K. The economic impact of smoking and of reducing smoking prevalence: review of evidence. Tob. Use Insights $\mathbf{8}$, 1-35 (2015).

6. World Health Organization. WHO Report on the Global Tobacco Epidemic, 2008: the MPOWER Package https://www.who.int/tobacco/mpower/2008/en/ (2008)

7. Chung-Hall, J., Craig, L., Gravely, S., Sansone, N. \& Fong, G. T. Impact of the WHO FCTC over the first decade: a global evidence review prepared for the Impact Assessment Expert Group. Tob. Control 28, s119-s128 (2019).

8. Reitsma, M. B. et al. Smoking prevalence and attributable disease burden in 195 countries and territories, 1990-2015: a systematic analysis from the Global Burden of Disease Study 2015. Lancet 389, 1885-1906 (2017).

9. Nilan, K., Raw, M., McKeever, T. M., Murray, R. L. \& McNeill, A. Progress in implementation of WHO FCTC Article 14 and its guidelines: a survey of tobacco dependence treatment provision in 142 countries. Addiction 112, 2023-2031 (2017).

10. Dubray, J., Schwartz, R., Chaiton, M., O’Connor, S. \& Cohen, J. E. The effect of MPOWER on smoking prevalence. Tob. Control 24, 540-542 (2015). 
11. Anderson, C. L., Becher, H. \& Winkler, V. Tobacco control progress in low and middle income countries in comparison to high income countries. Int. J. Environ. Res. Public Health 13, 1039 (2016).

12. Gravely, S. et al. Implementation of key demand-reduction measures of the WHO Framework Convention on Tobacco Control and change in smoking prevalence in 126 countries: an association study. Lancet Public Health 2, e166-e174 (2017).

13. Ngo, A., Cheng, K.-W., Chaloupka, F. J. \& Shang, C. The effect of MPOWER scores on cigarette smoking prevalence and consumption. Prev. Med. 105S, S10-S14 (2017).

14. Feliu, A. et al. Impact of tobacco control policies on smoking prevalence and quit ratios in 27 European Union countries from 2006 to 2014. Tob. Control 28, 101-109 (2019).

15. Greaves, L. Gender, equity and tobacco control. Health Sociol. Rev. 16, 115-129 (2007).

16. Amos, A., Greaves, L., Nichter, M. \& Bloch, M. Women and tobacco: a call for including gender in tobacco control research, policy and practice. Tob. Control 21, 236-243 (2012).

17. Hoffman, S. J. \& Tan, C. Overview of systematic reviews on the health-related effects of government tobacco control policies. BMC Public Health 15 , 744 (2015).

18. Chaloupka, F. J., Straif, K. \& Leon, M. E. Effectiveness of tax and price policies in tobacco control. Tob. Control 20, 235-238 (2011).

19. Rice, N., Godfrey, C., Slack, R., Sowden, A. \& Worthy, G. A Systematic Review of the Effects of Price on the Smoking Behaviour of Young People (Centre for Reviews and Dissemination, 2009); https://www.crd.york.ac.uk/crdweb/ ShowRecord.asp?LinkFrom=OAI\&ID=12013060057\&LinkFrom=OAI\& ID $=12013060057$

20. World Health Organizaion. WHO Report on the Global Tobacco Epidemic 2017: Monitoring Tobacco Use and Prevention Policies https://www.who.int/ tobacco/global_report/2017/en/ (2017).

21. Institute for Health Metrics and Evaluation. GBD Compare https://vizhub. healthdata.org/gbd-compare/ (2017).
22. Saffer, H. \& Chaloupka, F. The effect of tobacco advertising bans on tobacco consumption. J. Health Econ. 19, 1117-1137 (2000).

23. Noar, S. M. et al. The impact of strengthening cigarette pack warnings: systematic review of longitudinal observational studies. Soc. Sci. Med. 164, 118-129 (2016).

24. Moodie, C., Brose, L. S., Lee, H. S., Power, E. \& Bauld, L. How did smokers respond to standardised cigarette packaging with new, larger health warnings in the United Kingdom during the transition period? A cross-sectional online survey. Addict. Res. Theory 28, 53-61 (2020).

25. Wakefield, M. et al. Australian adult smokers' responses to plain packaging with larger graphic health warnings 1 year after implementation: results from a national cross-sectional tracking survey. Tob. Control 24, ii17-ii25 (2015)

26. Thun, M., Peto, R., Boreham, J. \& Lopez, A. D. Stages of the cigarette epidemic on entering its second century. Tob. Control 21, 96-101 (2012).

27. Bialous, S. A. Impact of implementation of the WHO FCTC on the tobacco industry's behaviour. Tob. Control 28, s94-s96 (2019).

Publisher's note Springer Nature remains neutral with regard to jurisdictional claims in published maps and institutional affiliations.

(c) (i) Open Access This article is licensed under a Creative Commons

Attribution 4.0 International License, which permits use, sharing, adaptation, distribution and reproduction in any medium or format, as long as you give appropriate credit to the original author(s) and the source, provide a link to the Creative Commons license, and indicate if changes were made. The images or other third party material in this article are included in the article's Creative Commons license, unless indicated otherwise in a credit line to the material. If material is not included in the article's Creative Commons license and your intended use is not permitted by statutory regulation or exceeds the permitted use, you will need to obtain permission directly from the copyright holder. To view a copy of this license, visit http://creativecommons. org/licenses/by/4.0/.

(C) The Author(s) 2021 


\section{Methods}

This was an ecological time series analysis that aimed to estimate the effect of four key demand reduction measures on smoking rates across 175 countries. Country-year-specific achievement scores for P, W and E measures and an affordability metric measured by RIP-to capture the impact of fiscal policy (R) - were included as predictors in the model. Although the WHO also calls for monitoring $(\mathrm{M})$ and tobacco cessation $(\mathrm{O})$ interventions, these were not evaluated. Monitoring tobacco use is not considered a demand reduction measure, while very little progress has been made in treatment provision over the last decade, Further information on research design is available in the Life Sciences Reporting Summary linked to this paper.

Smoking outcome data. The dependent variable is represented by country-specific, age-standardized estimates of current tobacco smoking prevalence, defined as individuals who currently use any smoked tobacco product on a daily or occasional basis. Complete time series estimates of smoking prevalence from 2009 to 2017 for men and women aged 15-29, $30-49,50$ years and older and 15 years and older, were taken from the Global Burden of Disease (GBD) 2017 study.

The GBD is a scientific effort to quantify the comparative magnitude of health loss due to diseases, injuries and risk factors by age, sex and geography for specific points in time. While full details on the estimation process for smoking prevalence have been published elsewhere, we briefly describe the main analytical steps in this article ${ }^{3}$. First, 2,870 nationally representative surveys meeting the inclusion criteria were systematically identified and extracted. Since case definitions vary between surveys, for example, some surveys only ask about daily smoking as opposed to current smoking that includes both daily and occasional smokers, the extracted data were adjusted to the reference case definition using a linear regression fit on surveys reporting multiple case definitions. Next, for surveys with only tabulated data available, nonstandard age groups and data reported as both sexes combined were split using observed age and sex patterns. These preprocessing steps ensured that all data used in the modeling were comparable. Finally, spatiotemporal Gaussian process regression, a three-step modeling process used extensively in the GBD to estimate risk factor exposure, was used to estimate a complete time series for every country, age and sex. In the first step, estimates of tobacco consumption from supply-side data are incorporated to guide general levels and trends in prevalence estimates. In the second step, patterns observed in locations, age groups and years with smoking prevalence data are synthesized to improve the first-step estimates. This step is particularly important for countries and time periods with limited or no available prevalence data. The third step incorporates and quantifies uncertainty from sampling error, non-sampling error and the preprocessing data adjustments. For this analysis, the final age-specific estimates were age-standardized using the standard population based on GBD population estimates. Age standardization, while less important for the narrower age groups, ensured that the estimated effects of policies were not due to differences in population structure, either within or between countries.

Using GBD-modeled data is a strength of the study since nearly 3,000 surveys inform estimates and countries are not required to have complete survey coverage between 2009 and 2017 to be included in the analysis. Yet, it is important to note that these estimates have limitations. For example, in countries where a prevalence survey was not conducted after the enactment of a policy, modeled estimates may not reflect changes in prevalence resulting from that policy. Nonetheless, the prevalence estimates from the GBD used in this study are similar to those presented in the latest $\mathrm{WHO}$ repor ${ }^{28}$, indicating the validity and consistency of said estimates.

MPOWER data. Summary indicators of country-specific achievements for each MPOWER measure are released by the WHO every two years and date back to 2007. Data from different iterations of the WHO Report on the Global Tobacco Epidemic $\left(2008^{6}, 2009^{29}, 2011^{30}, 2013^{31}, 2015^{32}\right.$ and $\left.2017^{20}\right)$ were downloaded from the WHO Tobacco Free Initiative website (https://www.who.int/tobacco/ about/en/). To assess the quality of national-level legislation, the WHO attributes a score to each MPOWER component that ranges from 1 to 4 for the monitoring (M) dimension and 1-5 for the other dimensions. A score of 1 represents no known data or no recent data, while scores $2-5$ characterize the overall strength of each policy, from the lowest level of achievement (weakest policy) to the highest (strongest policy).

Specifically, smoke-free legislation $(\mathrm{P})$ is assessed to determine whether smoke-free laws provide for a complete indoor smoke-free environment at all times in each of the respective places: healthcare facilities; educational facilities other than universities; universities; government facilities; indoor offices and workplaces not considered in any other category; restaurants or facilities that serve mostly food; cafes, pubs and bars or facilities that serve mostly beverages; and public transport. Achievement scores are then based on the number of places where indoor smoking is completely prohibited. Regarding health warning policies $(\mathrm{W})$, the size of the warnings on both the front and back of the cigarette pack are averaged to calculate the percentage of the total pack surface area covered by the warning. This information is combined with seven best practice warning characteristics to construct policy scores for the $\mathrm{W}$ dimension. Finally, countries achievements in banning tobacco advertising, promotion and sponsorship (E) are assessed based on whether bans cover the following types of direct and indirect advertising: (1) direct: national television and radio; local magazines and newspapers; billboards and outdoor advertising; and point of sale (indoors); (2) indirect: free distribution of tobacco products in the mail or through other means; promotional discounts; nontobacco products identified with tobacco brand names; brand names of nontobacco products used or tobacco products; appearance of tobacco brands or products in television and/or films; and sponsorship.

$\mathrm{P}, \mathrm{W}$ and $\mathrm{E}$ achievement scores, ranging from 2 to 5 , were included as predictors into the model. The goal was to not only capture the effect of adopting policies at its highest levels but also assess the reduction in prevalence that could be achieved if countries moved into the expected direction in terms of implementing stronger measures over time. Additionally, having P, W and E scores separately, and not combined into a composite score, enabled us to capture the independent effect of different types of policies.

Although compliance is a critical factor in understanding policy effectiveness, the achievement scores incorporated in our main analysis reflect the adoption of legislation rather than degree of enforcement, representing a limitation of these indicators.

Price data. Prices in I\$ for a 20-cigarette pack of the most sold brand in each of the 175 countries were also sourced from the WHO Tobacco Free Initiative website for all available years $(2008,2010,2012,2014$ and 2016). I\$ standardize prices across countries and also adjust for inflation across time. This information was used to construct an affordability metric that captures the impact of cigarette prices on smoking prevalence, considering the income level of each country.

More specifically, the RIP, calculated as the percentage of per capita GDP required to purchase one half pack of cigarettes a day over the course of a year, was computed for each available country and year. Per capita GDP estimates were drawn from the Institute for Health Metrics and Evaluation; the estimation process is detailed elsewhere ${ }^{33}$

Given that the price data used in the analysis refer to the most sold brand of cigarettes only, it does not reflect the full range of prices of different types of tobacco products available in each location. This might particularly affect our power in detecting a strong effect in countries where other forms of tobacco are more popular.

Statistical analysis. Sex- and age-specific logit-transformed prevalence estimates from 2009 to 2017 were matched to one-year lagged achievement scores and RIP values using country and year identifier ${ }^{34}$. The final sample consisted of 175 countries and was constrained to locations and years with non-missing indicators. A multiple linear mixed effects model fitted by restricted maximum likelihood was used to assess the independent effect of $\mathrm{P}, \mathrm{W}$ and $\mathrm{E}$ scores and RIP values on the rates of current smoking. Specifically, a country random intercept and a country random slope on RIP were included to account for geographical heterogeneity and within-country correlation. The regression model takes the following general form:

$\operatorname{logit}\left(y_{c, t}\right)=\beta_{0}+\beta_{p} \mathrm{P}_{c, t-1}+\beta_{w} \mathrm{~W}_{c, t-1}+\beta_{e} \mathrm{E}_{c, t-1}+\beta_{r} \mathrm{R}_{c, t-1}+\alpha_{c}+\delta_{c} \mathrm{R}_{c, t-1}+\epsilon_{c, t}$

where $y_{c, t}$ is the prevalence of current smoking in each country $(c)$ and year $(t)$, $\beta_{0}$ is the intercept for the model and $\beta_{\mathrm{p}}, \beta_{\mathrm{w}}, \beta_{\mathrm{e}}$ and $\beta_{\mathrm{r}}$ are the fixed effects for each of the policy predictors. $\mathrm{P}_{c, t-1}, \mathrm{~W}_{c, t-1}, \mathrm{E}_{c, t-1}$ are the $\mathrm{P}, \mathrm{W}$ and $\mathrm{E}$ scores and $\mathrm{R}_{c, t-1}$ is the RIP value for country $c$ in year $t-1$. Finally, $\alpha_{c}$ is the random intercept for country $(c)$, while $\delta_{c}$ represent the random slope for the country $(c)$ to which the RIP value $\left(\mathrm{R}_{t-1}\right)$ belongs. Variance inflation factor values were calculated for all the predictor parameters to check for multicollinearity; the values found were low $(<2)^{35}$. Bivariate models were also run and are shown in Extended Data Fig. 5. The one-year lag introduced into the model may have led to an underestimation of effect sizes, particularly as many MPOWER policies require a greater period of time to be implemented effectively. However, due to the limited time range of our data (spanning eight years in total), introducing a longer lag period would have resulted in the loss of additional data points, thus further limiting our statistical power in detecting relevant associations between policies and smoking prevalence.

In addition to a joint model for smokers from both sexes, separate regressions were fitted for men and women and the four age groups (15-29, 30-49, $\geq 50$ and $\geq 15$ years old). To assess the validity of the mixed effects analyses, likelihood ratio tests comparing the models with random effects to the null models with only fixed effects were performed. Linear mixed models were fitted by maximum likelihood and $t$-tests used Satterthwaite approximations to degrees of freedom. $P$ values were considered statistically significant if $<0.05$. All analyses were executed with RStudio v.1.1.383 using the lmer function in the R package lme4 v.1.1-21 (ref. ${ }^{36}$ ).

A series of additional models to examine the impact of tobacco control policies were developed as part of this study. In each model, cigarette affordability (RIP) and a different set of policy metrics was used to capture the implementation, quality and compliance of tobacco control legislation. In models 1 and 2, we replaced the achievements scores by the proportion of $\mathrm{P}, \mathrm{W}$ and $\mathrm{E}$ measures adopted by each country out of all possible measures reported by the WHO. In model 3, we used P and E (direct and indirect measures separately) compliance scores provided by the WHO to represent actual legislation implementation. 
Finally, an interaction term for compliance and achievement to capture the combined effect of legislation quality and performance was added to model 4 . Results for men and women by age group for each of the additional models are presented in the Supplemental Information (Supplementary Tables 1-4).

The main model described in this study was chosen because it includes a larger number of country-year observations $(n=823)$ when compared to models including compliance scores and because it is more directly interpretable.

Counterfactual analysis. To further explore and quantify the impact of tobacco control policies on current smoking prevalence, we simulated what smoking prevalence across all countries would have been achieved in 2017 under 4 alternative policy scenarios: (1) if achievement scores and RIP remained at the level they were at in 2008; (2) if all countries had implemented each of P, W and E component at the highest level (score =5); (3) if the price of a cigarette pack was $I \$ 7.73$ or higher, a price that represents the 90 th percentile of observed prices across all countries and years; and (4) if countries had implemented the P, W and $\mathrm{E}$ components at the highest level and higher cigarette prices. To keep our results consistent across scenarios, we restricted our analysis to 155 countries with non-missing policy-related indicators for both 2008 and 2016.

Random effects were used in model fitting but not in this prediction. Simulated prevalence rates were calculated by multiplying the estimated marginal effect of each policy by the alternative values proposed in each of the counterfactual scenarios for each country-year. The global population-weighted average was computed for status quo and counterfactual scenarios using population data sourced from the Institute for Health Metrics and Evaluation. Using the predicted prevalence rates and population data, the additional reduction in the number of current smokers in 2017 was also computed. Since models were ran using age-standardized prevalence, the number of smokers was proportionally redistributed across age groups using the sex-specific numbers from the age group 15 and older as an envelope.

The UIs for predicted estimates were based on a computation of the results of each of the 1,000 draws (unbiased random samples) taken from the uncertainty distribution of each of the estimated coefficients; the lower bound of the 95\% UI for the final quantity of interest is the 2.5 percentile of the distribution and the upper bound is the 97.5 percentile of the distribution.

Reporting Summary. Further information on research design is available in the Nature Research Reporting Summary linked to this article.

\section{Data availability}

The dataset generated and analyzed during the current study is publicly available at http://ghdx.healthdata.org/record/ihme-data/ global-tobacco-control-and-smoking-prevalence-scenarios-2017 (https://doi. org/10.6069/QAZ7-6505). The dataset contains all data necessary to interpret, replicate and build on the methods or findings reported in the article. Tobacco control policy data that support the findings of this study are released every two years as part of the WHO's Global Report on Tobacco Control; these data are also directly accessible at https://www.who.int/tobacco/global_report/en/. Source data are provided with this paper.

\section{Code availability}

All code used for these analyses is available at http://ghdx.healthdata.org/record/ ihme-data/global-tobacco-control-and-smoking-prevalence-scenarios-2017 and https://github.com/ihmeuw/team/tree/effects_tobacco_policies.

\section{References}

28. World Health Organization. Global Report on Trends in Prevalence of Tobacco Smoking 2000-2025 http://www.who.int/tobacco/publications/surveillance/ trends-tobacco-smoking-second-edition/en/ (2018).
29. World Health Organization. WHO Report on the Global Tobacco Epidemic 2009: Implementing Smoke-Free Environments https://www.who.int/tobacco/ mpower/2009/en/ (2009).

30. World Health Organization. WHO Report on the Global Tobacco Epidemic 2011: Warning About the Dangers of Tobacco https://www.who.int/tobacco/ global_report/2011/en/ (2011).

31. World Health Organization. WHO Report on the Global Tobacco Epidemic 2013: Enforcing Bans on Tobacco Advertising, Promotion and Sponsorship https://www.who.int/tobacco/global_report/2013/en/ (2013).

32. World Health Organization. WHO Report on the Global Tobacco Epidemic 2015: Raising Taxes on Tobacco https://www.who.int/tobacco/global_ report/2015/en/ (2015).

33. James, S. L., Gubbins, P., Murray, C. J. \& Gakidou, E. Developing a comprehensive time series of GDP per capita for 210 countries from 1950 to 2015. Popul. Health Metr. 10, 12 (2012).

34. Institute for Health Metrics and Evaluation. Global Tobacco Control and Smoking Prevalence Scenarios 2017 (dataset) (Global Health Data Exchange, 2020).

35. Zuur, A. F., Ieno, E. N. \& Elphick, C. S. A protocol for data exploration to avoid common statistical problems. Methods Ecol. Evol. 1, 3-14 (2010).

36. Bates, D., Mächler, M., Bolker, B. \& Walker, S. Fitting linear mixed-effects models using lme4. J. Stat. Softw. https://doi.org/10.18637/jss.v067.i01 (2015).

\section{Acknowledgements}

The study was funded by Bloomberg Philanthropies (grant 47386, Initiative to Reduce Tobacco Use). We thank the support of the Tobacco Metrics Team Advisory Group, which provided valuable comments and suggestions over several iterations of this manuscript. We also thank the Tobacco Free Initiative team at the WHO and the Campaign for Tobacco-Free Kids for making the tobacco control legislation data available and providing clarifications when necessary. We thank A. Tapp, E. Mullany and J. Whisnant for assisting in the management and execution of this study. We thank the team who worked in a previous iteration of this project, especially A. Reynolds, C. Margono, E. Dansereau, K. Bolt, M. Subart and X. Dai. Lastly, we thank all GBD 2017 Tobacco collaborators for their valuable work in providing feedback to our smoking prevalence estimates throughout the GBD 2017 cycle.

\section{Author contributions}

L.S.F., M.N. and E.G. conceptualized the study and designed the analytical framework. M.B.R. and V.G. provided input on data, results and interpretation. L.S.F. and E.G. wrote the first draft of the manuscript. All authors read and approved the final version of the manuscript.

\section{Competing interests}

The authors declare no competing interests.

\section{Additional information}

Extended data is available for this paper at https://doi.org/10.1038/s41591-020-01210-8.

Supplementary information The online version contains supplementary material available at https://doi.org/10.1038/s41591-020-01210-8.

Correspondence and requests for materials should be addressed to E.G.

Peer review information Jennifer Sargent was the primary editor on this article and managed its editorial process and peer review in collaboration with the rest of the editorial team.

Reprints and permissions information is available at www.nature.com/reprints. 
A
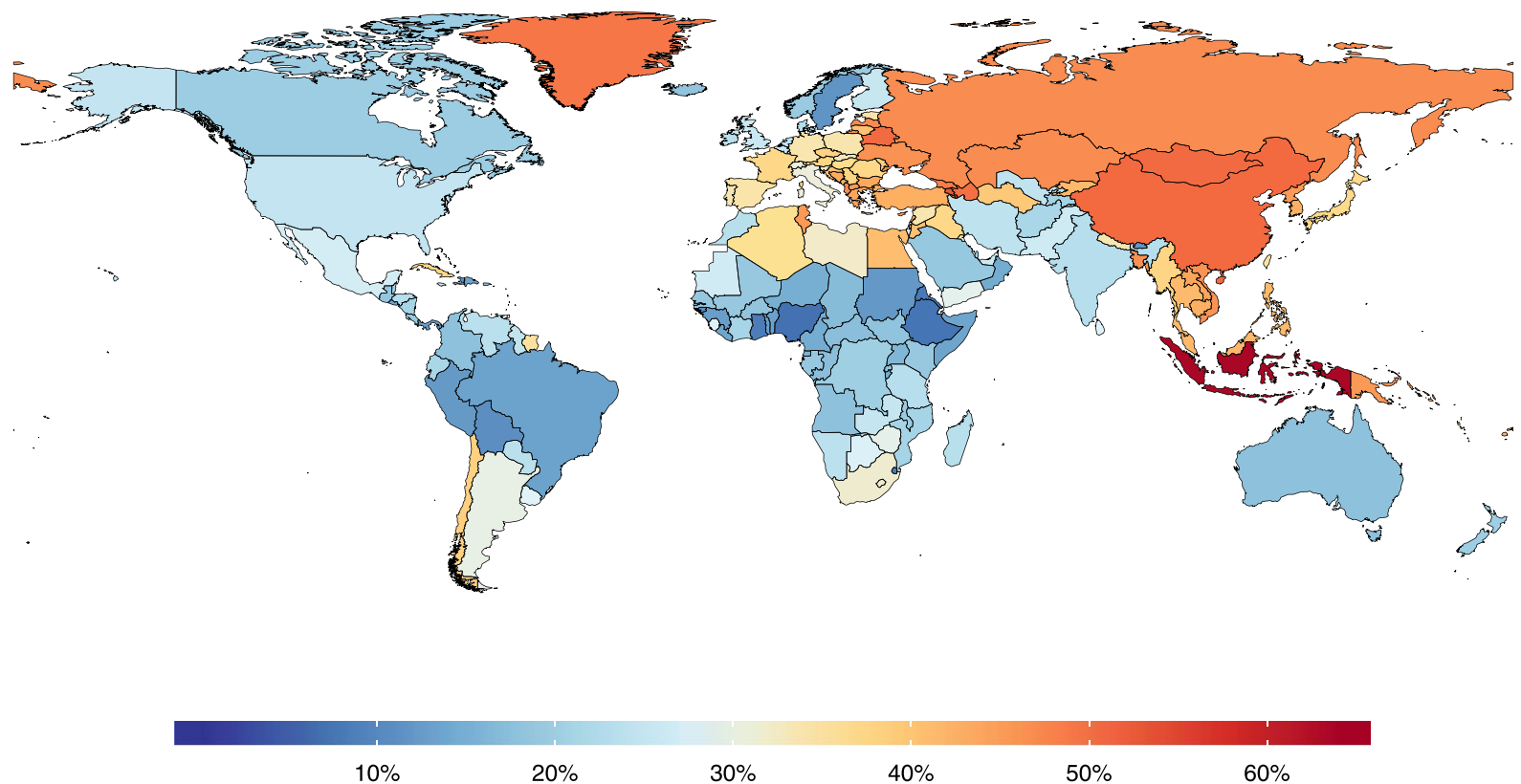

B

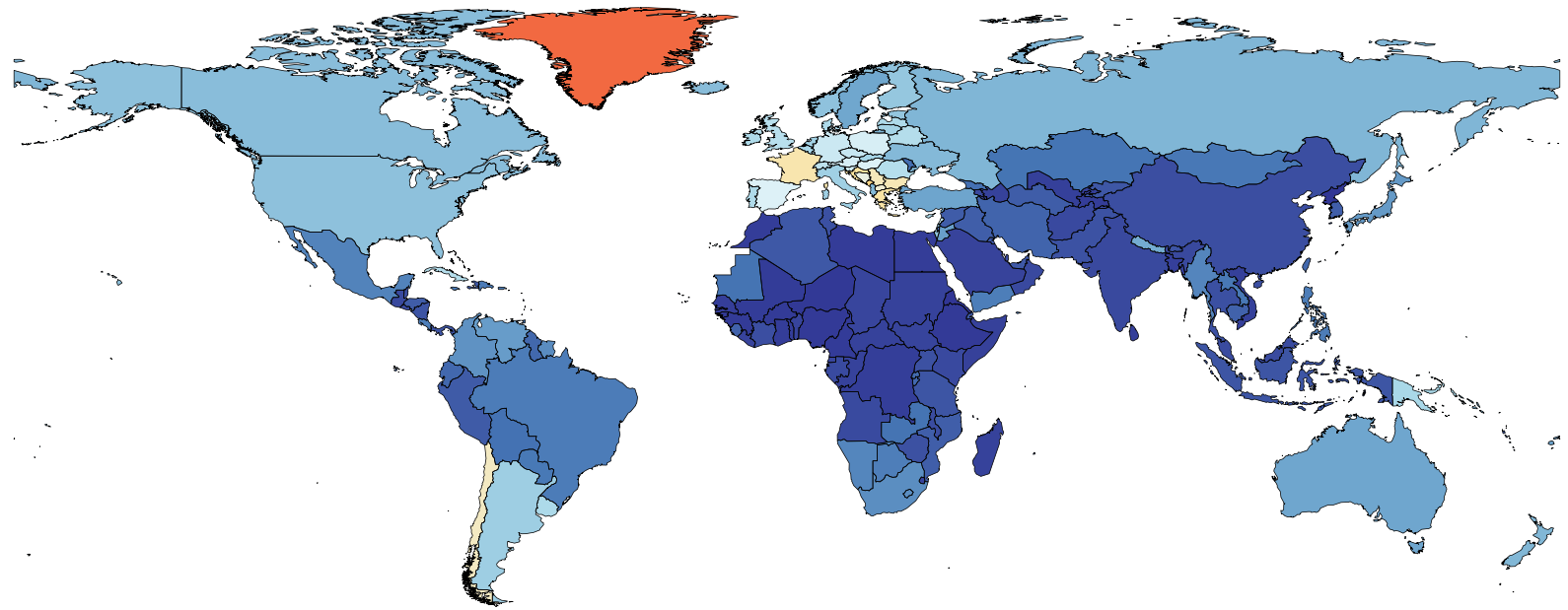

$10 \%$

$20 \%$

$30 \%$

$40 \%$

$50 \%$

$60 \%$

Extended Data Fig. 1 | Prevalence of current smoking for men (a) and women (b) aged 15 years and older (age-standardized) in 2017. Age-standardized smoking prevalence (\%) estimates from the 2017 Global Burden of Disease Study for men (a) and women (b) aged 15 years and older for 195 countries. Smoking is defined as current use of any type of smoked tobacco product. Details on the estimation process can be found in the Methods section and elsewhere ${ }^{3}$. 
A
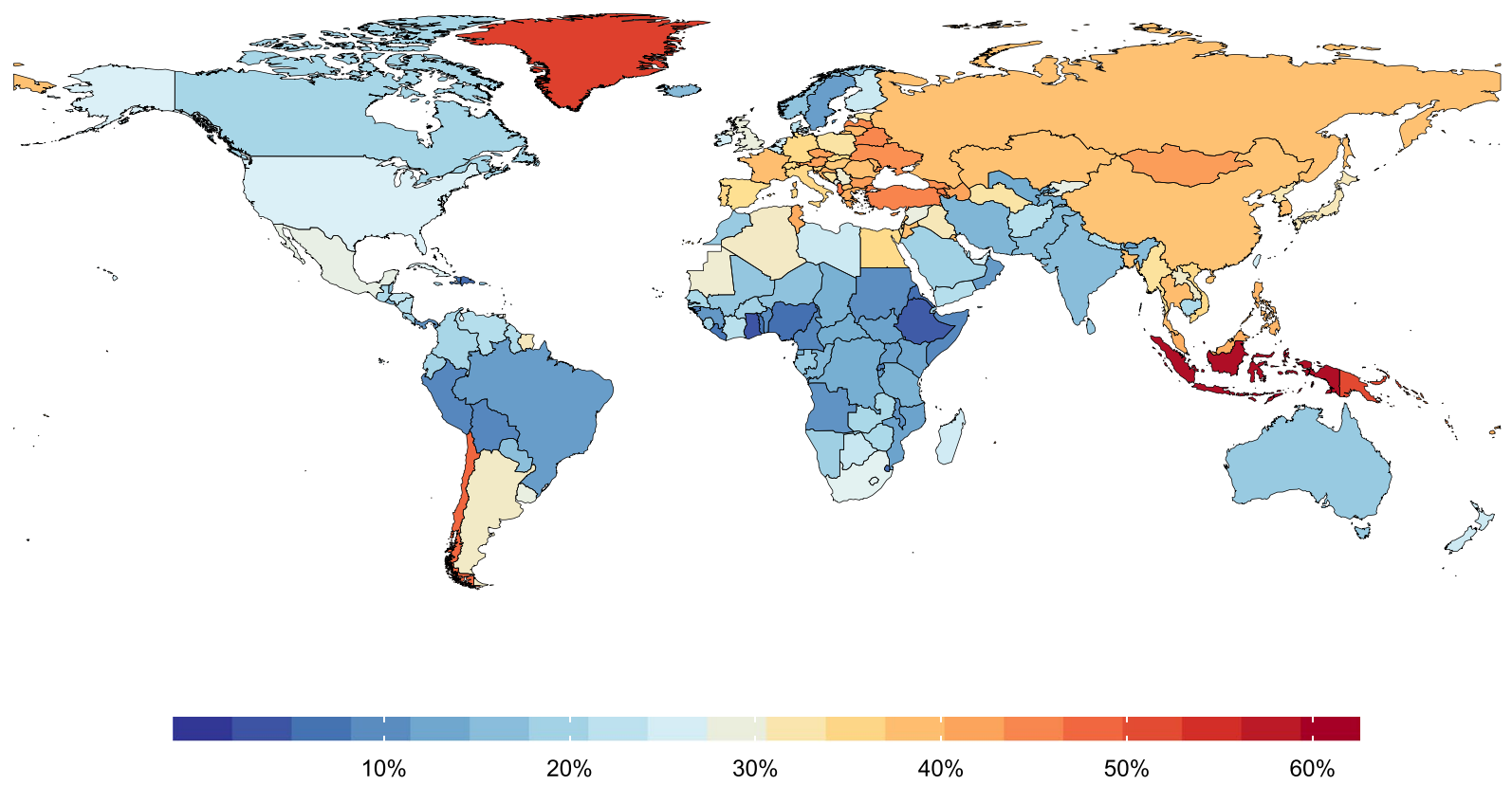

B

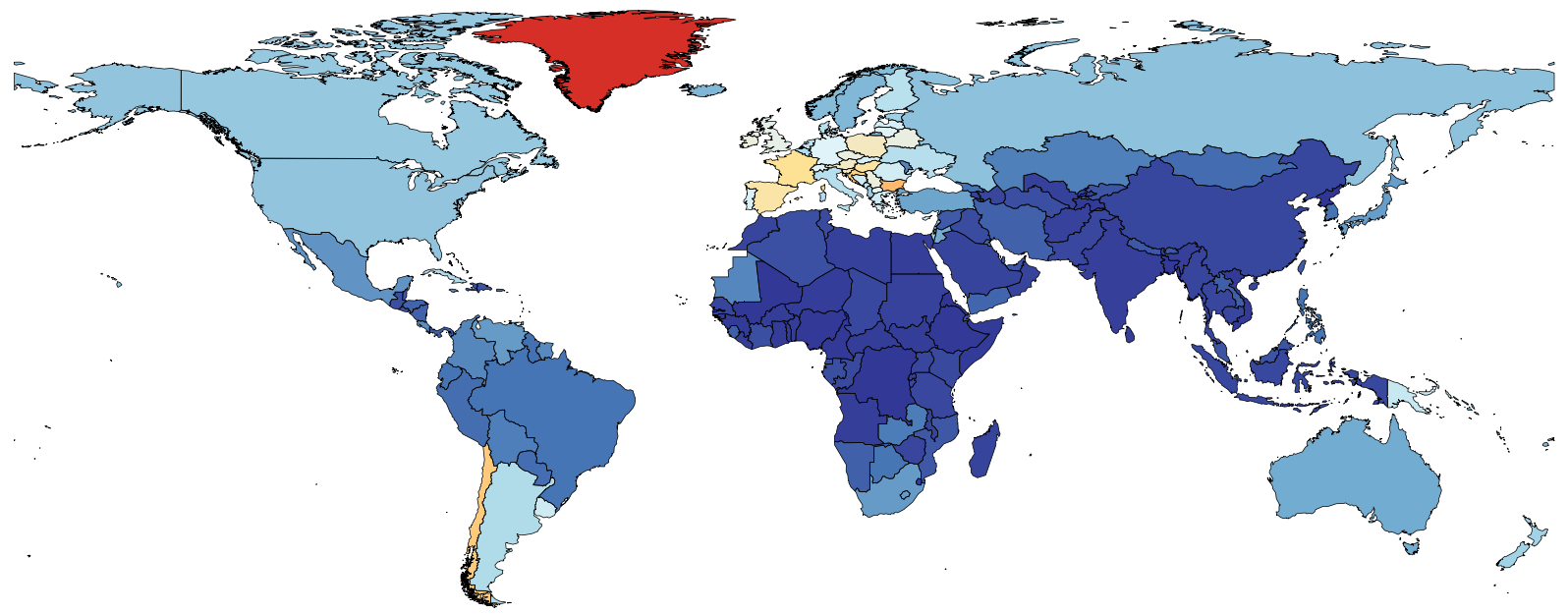

$10 \%$

$20 \%$

$30 \%$

$40 \%$

$50 \%$

$60 \%$

Extended Data Fig. 2 | Prevalence of current smoking for men (a) and women (b) aged 15 to 29 years old (age-standardized) in 2017. Age-standardized smoking prevalence (\%) estimates from the 2017 Global Burden of Disease Study for men (a) and women (b) aged 15-29 years old for 195 countries. Smoking is defined as current use of any type of smoked tobacco product. Details on the estimation process can be found in the Methods section and elsewhere ${ }^{3}$. 
A
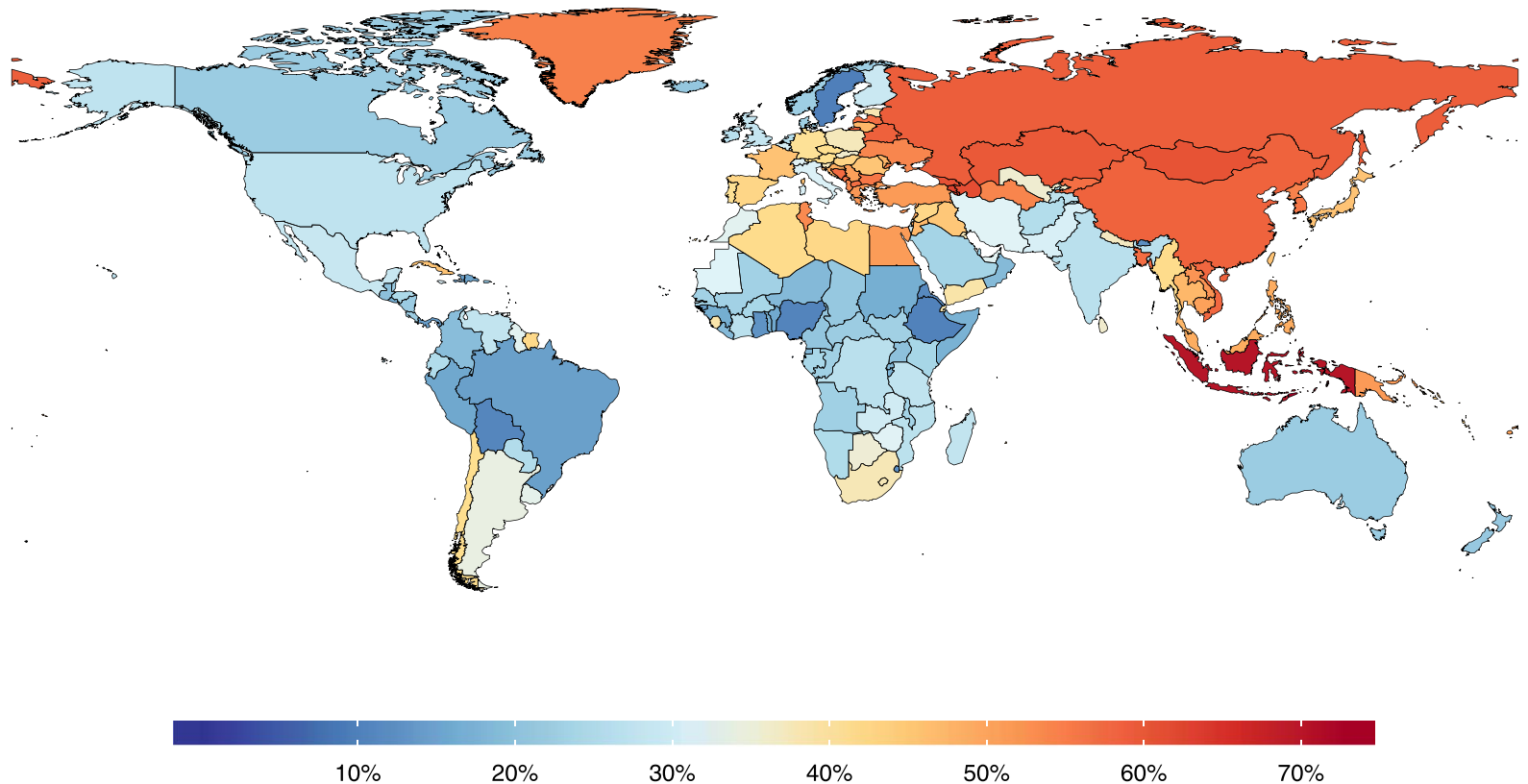

B

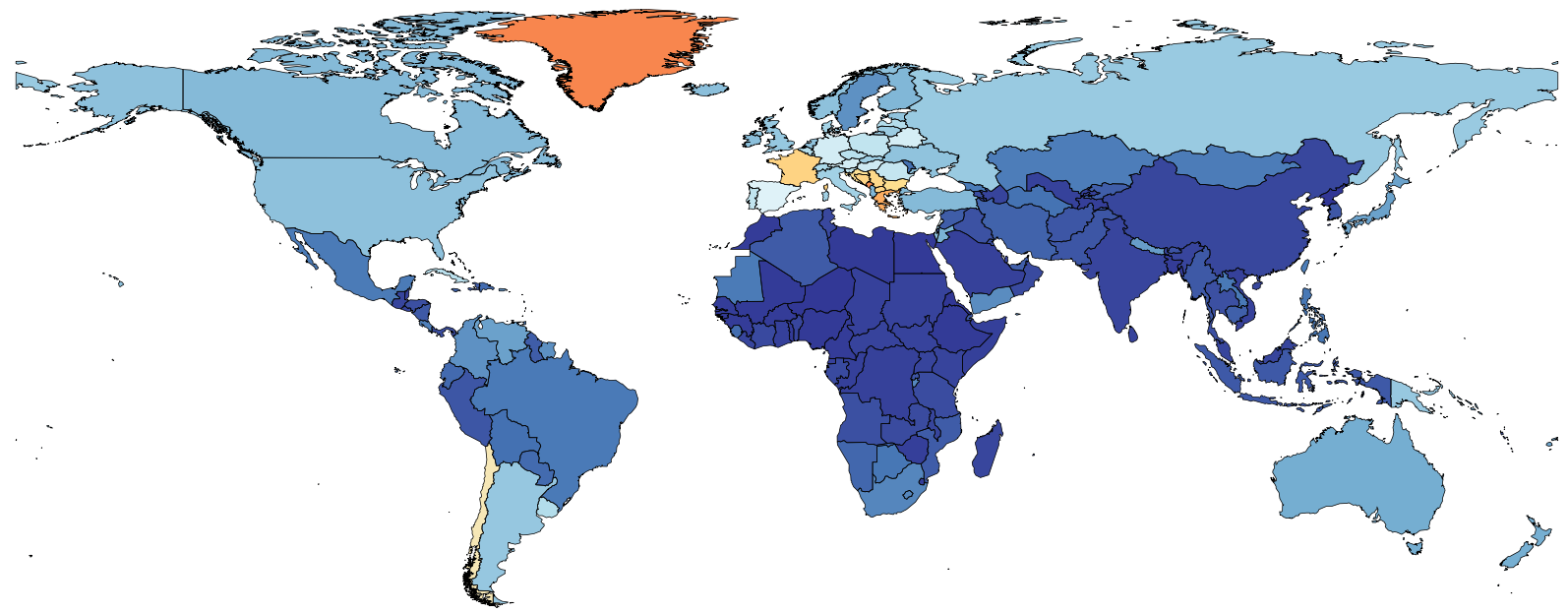

$10 \%$

$20 \%$

$30 \%$

$40 \%$

$50 \%$

$60 \%$

$70 \%$

Extended Data Fig. 3 | Prevalence of current smoking for men (a) and women (b) aged 30 to 49 years old (age-standardized) in 2017. Age-standardized smoking prevalence (\%) estimates from the 2017 Global Burden of Disease Study for men (a) and women (b) aged 30-49 years old for 195 countries. Smoking is defined as current use of any type of smoked tobacco product. Details on the estimation process can be found in the Methods section and elsewhere ${ }^{3}$. 
A
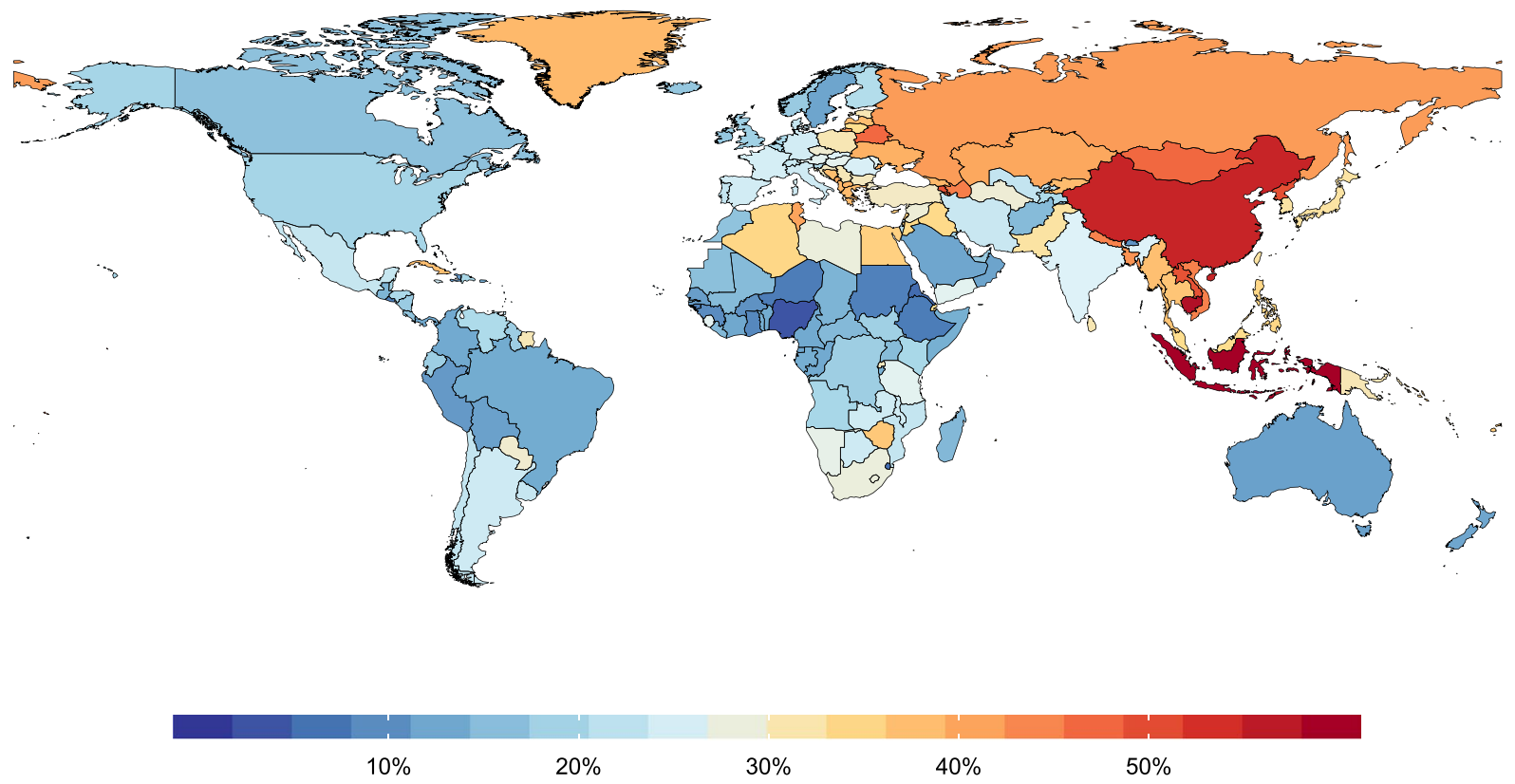

B

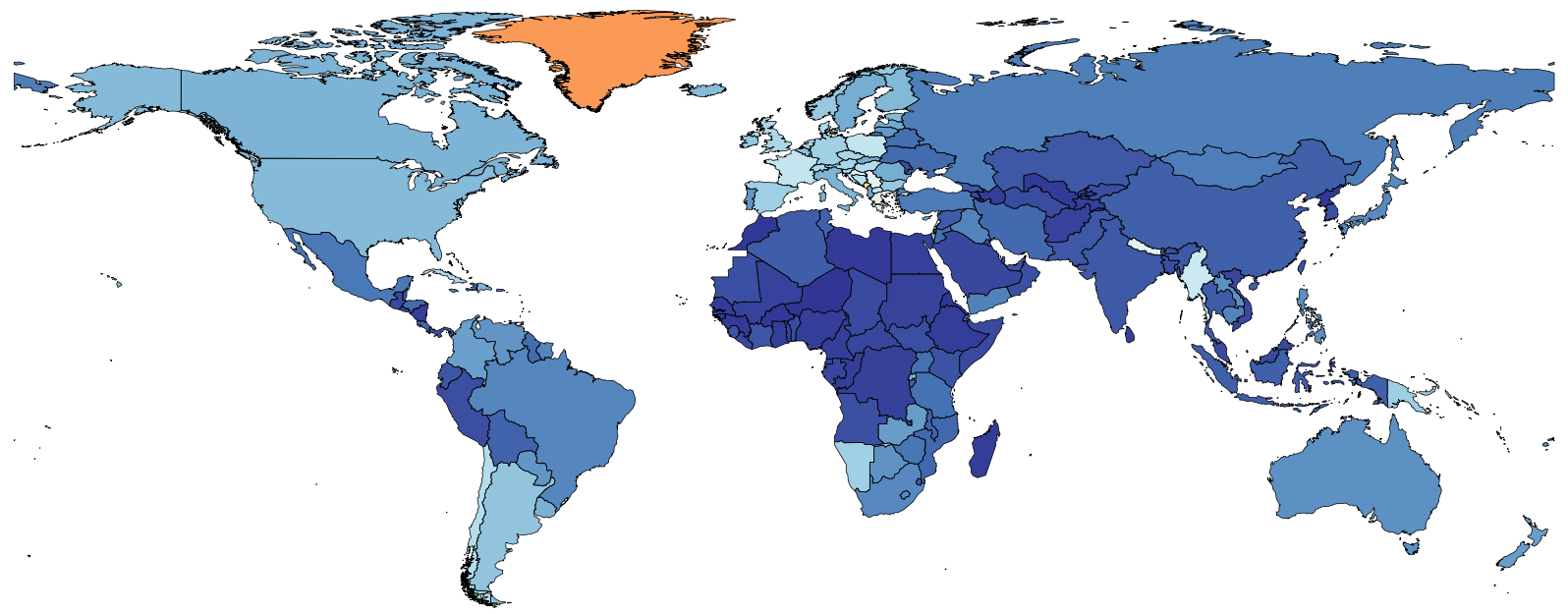

Extended Data Fig. 4 | Prevalence of current smoking for men (a) and women (b) aged 50 years and older (age-standardized) in 2017.

Age-standardized smoking prevalence (\%) estimates from the 2017 Global Burden of Disease Study for men (a) and women (b) aged 50 years and older for 195 countries. Smoking is defined as current use of any type of smoked tobacco product. Details on the estimation process can be found in the Methods section and elsewhere ${ }^{3}$. 


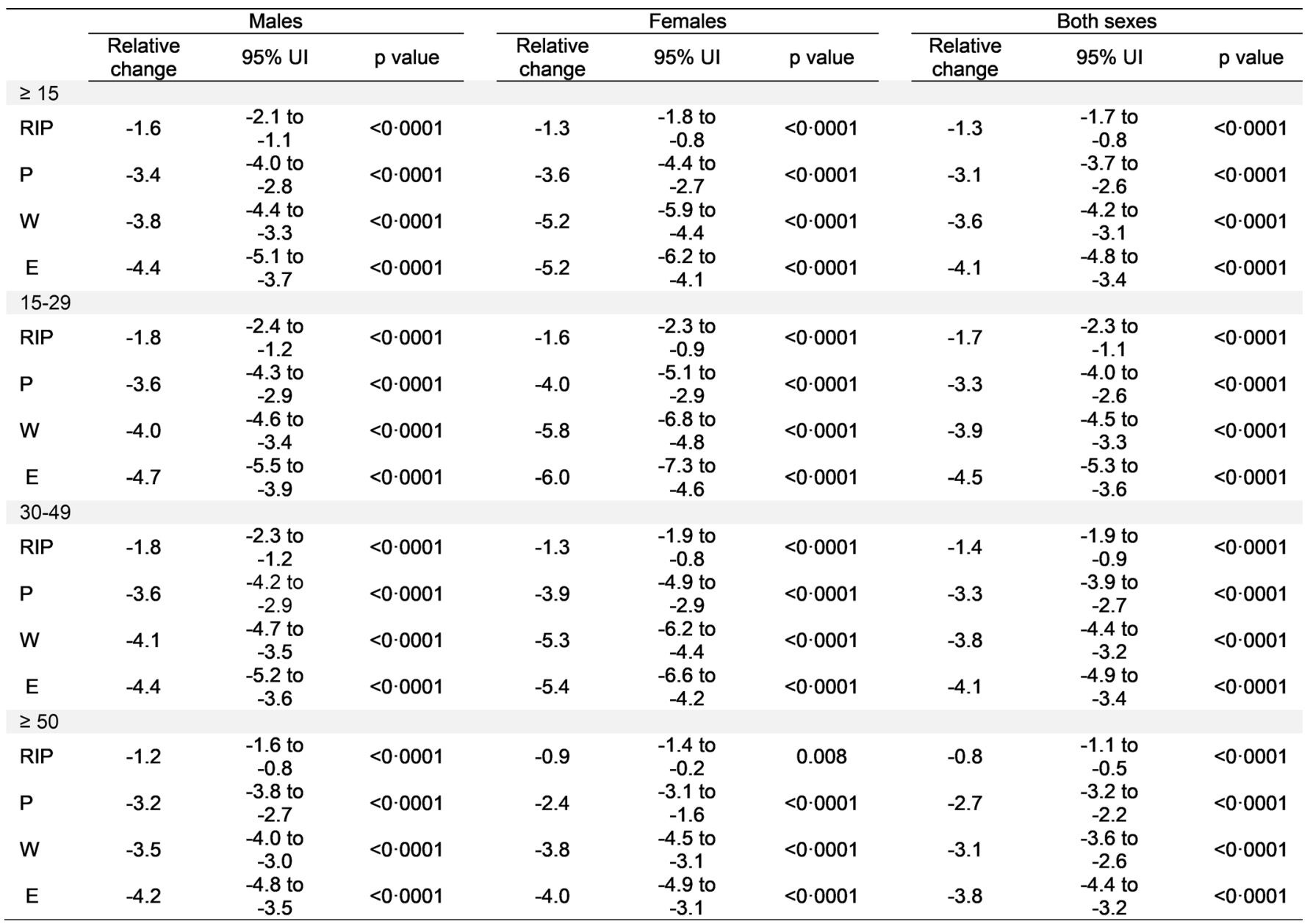

Extended Data Fig. 5 | Percentage changes in current smoking prevalence based on fixed effect coefficients from bivariate mixed effect linear regression models, by policy component, sex and age group. Bivariate models examined the unadjusted association between smoke-free (P), health warnings (W), and advertising (E) achievement scores, and cigarette's affordability (RIP) and current smoking prevalence, from 2009 to 2017 , across 175 countries ( $n=823$ country-years). Linear mixed models were fit by maximum likelihood and t-tests used Satterthwaite approximations to degrees of freedom. $P$ values were considered statistically significant if lower than 0.05 . 


\section{Reporting Summary}

Nature Research wishes to improve the reproducibility of the work that we publish. This form provides structure for consistency and transparency in reporting. For further information on Nature Research policies, see our Editorial Policies and the Editorial Policy Checklist.

\section{Statistics}

For all statistical analyses, confirm that the following items are present in the figure legend, table legend, main text, or Methods section.

$\mathrm{n} / \mathrm{a}$ Confirmed

$\bigotimes$ The exact sample size $(n)$ for each experimental group/condition, given as a discrete number and unit of measurement

$\bigotimes$ A statement on whether measurements were taken from distinct samples or whether the same sample was measured repeatedly

The statistical test(s) used AND whether they are one- or two-sided

Only common tests should be described solely by name; describe more complex techniques in the Methods section.

$\bigotimes$ A description of all covariates tested

Х $\square$ A description of any assumptions or corrections, such as tests of normality and adjustment for multiple comparisons

$\square$ A full description of the statistical parameters including central tendency (e.g. means) or other basic estimates (e.g. regression coefficient)

AND variation (e.g. standard deviation) or associated estimates of uncertainty (e.g. confidence intervals)

For null hypothesis testing, the test statistic (e.g. $F, t, r$ ) with confidence intervals, effect sizes, degrees of freedom and $P$ value noted Give $P$ values as exact values whenever suitable.

Х $\square$ For Bayesian analysis, information on the choice of priors and Markov chain Monte Carlo settings

$\square$ For hierarchical and complex designs, identification of the appropriate level for tests and full reporting of outcomes

$\triangle \square$ Estimates of effect sizes (e.g. Cohen's $d$, Pearson's $r$ ), indicating how they were calculated

Our web collection on statistics for biologists contains articles on many of the points above.

\section{Software and code}

Policy information about availability of computer code

Data collection No primary data collection was carried out for this analysis.

Data analysis All analyses were executed with RStudio (version 1.1.383) using the Imer function in the R package Ime4.

For manuscripts utilizing custom algorithms or software that are central to the research but not yet described in published literature, software must be made available to editors and

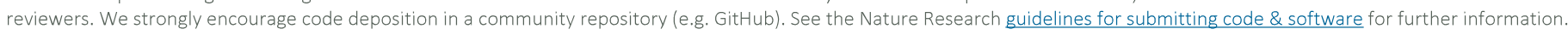

\section{Data}

Policy information about availability of data

All manuscripts must include a data availability statement. This statement should provide the following information, where applicable:

- Accession codes, unique identifiers, or web links for publicly available datasets

- A list of figures that have associated raw data

- A description of any restrictions on data availability

The dataset generated and analyzed during the current study is openly available at http://ghdx.healthdata.org/record/ihme-data/global-tobacco-control-andsmoking-prevalence-scenarios-2017 (DOI: 10.6069/QAZ7-6505). The dataset contains all data necessary to interpret, replicate and build upon the methods or findings reported in the article. Tobacco control policy data that support the findings of this study are released every two years as part of WHO's Global Report on

Tobacco Control, which are also directly accessible at https://www.who.int/tobacco/global_report/en/. 
Please select the one below that is the best fit for your research. If you are not sure, read the appropriate sections before making your selection.

\ Life sciences

Behavioural \& social sciences

Ecological, evolutionary \& environmental sciences

For a reference copy of the document with all sections, see nature.com/documents/nr-reporting-summary-flat.pdf

\section{Life sciences study design}

All studies must disclose on these points even when the disclosure is negative.

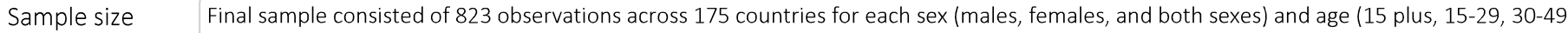
and 50 plus) specific models. No sample size was calculated because all country-years with available smoking prevalence estimate and national level data on cigarette prices and policy achievement scores were included in the analysis. Specifically for the analysis of counterfactual scenarios, all 155 countries with non-missing policy indicators for both 2008 and 2016 were included, as described in the methods section.

Data exclusions As described in the methods section of the main text, country-year observations were excluded if any indicator - smoking prevalence, cigarette prices, and policy achievement scores - was missing. Out of the 195 countries with estimated smoking prevalence in the $2017 \mathrm{Global}$ Burden of Disease study, 20 had no tobacco control indicators for any year between 2008 and 2016 and were not included in our models. Additional 20 countries were excluded in our counterfactual analysis due to lack of availability of cigarettes prices and/or policy achievement scores in both 2008 and 2016. The decision to exclude these locations from our entire conterfactual analysis was to keep our pooled estimated reduction in prevalence consistent across alternative scenarios (same number of countries were included for each scenario prediction).

Replication $\quad$ This is an observational study using multiple years of smoking prevalence estimates (2009-2017) and publicly available national-level tobacco control policy data (2008-2016)

Randomization This analysis is an observational study and there were no experimental groups.

Blinding

Blinding was not relevant to this study, as it was an observational study using survey data and publicly available tobacco control policy indicators.

\section{Reporting for specific materials, systems and methods}

We require information from authors about some types of materials, experimental systems and methods used in many studies. Here, indicate whether each material, system or method listed is relevant to your study. If you are not sure if a list item applies to your research, read the appropriate section before selecting a response.

\begin{tabular}{|c|c|}
\hline$n / a$ & Involved in the study \\
\hline$\bigotimes$ & $\square$ Antibodies \\
\hline Х & $\square$ Eukaryotic cell lines \\
\hline Х & $\square$ Palaeontology and archaeology \\
\hline Х & $\square$ Animals and other organisms \\
\hline Х & $\square$ Human research participants \\
\hline Х & $\square$ Clinical data \\
\hline$\bigotimes$ & $\square$ Dual use research of concern \\
\hline
\end{tabular}

\begin{tabular}{|c|c|}
\hline $\mathrm{n} / \mathrm{a}$ & Involved in the study \\
\hline Х & $\square$ ChIP-seq \\
\hline Х & $\square$ Flow cytometry \\
\hline Х & $\square$ MRI-based neuroimaging \\
\hline
\end{tabular}

